\title{
Report of the Working Party of the Endoscopy Committee of the British Society of Gastroenterology on the reuse of endoscopic accessories
}

\section{History and regulatory position}

There is a long tradition in the UK of reusing all endoscopic accessories until they break or are degraded to an unusable extent, regardless of manufacturers' recommendations. This has stemmed largely from a desire to eke out the meagre funds generally allotted to gastroenterology/endoscopy departments for equipment. This attitude has been changing gradually, with the increasing sale of single use items, for example, varices injection needles, but the scene has been changed completely since the publication of the Medical Devices Agency Bulletin, MDA DB 9501, in January $1995^{1}$ and the implementation of the European Medical Devices Directive. ${ }^{2}$

The former bulletin states that products labelled as single use: “...should not be reprocessed and reused unless the reprocessor:

- is able to apply and observe all the stringent technical requirements necessary to ensure the integrity and safety in use of each reprocessed item;

- can produce documentary proof and evidence of successful validation studies of the reprocessing operation. These studies are for the purpose of confirming that the reprocessing method chosen produces a safe and effective product, fit for the intended purpose; and

- has a system for retaining full reprocessing batch records, for subsequent retrieval in the event of device failure and patient injury.

Users who disregard this information and prepare single use products for further use, without due precautions, may be transferring legal liability for the safe performance of the product from the manufacturer to themselves, or to the organisation that employs them."

The EEC document examined the whole question of the suitability of medical devices for their purposes and promulgated the system of CE marking which has been implemented from 1 January 1995 and, following a transition period, will be mandatory from 14 June 1998. This directive refers in Annex IX, 1.3 to a reusable surgical instrument as one: "which can be reused after appropriate procedures have been carried out". Where the device has been supplied as a reusable item, the label must bear the following particulars:

" 13.6 (h) if the device is reusable, information on the appropriate processes to allow reuse, including cleaning, disinfection, packaging and, where appropriate, the method of sterilisation of the device to be resterilised, and any restrictions on the number of reuses.

Where devices are supplied with the intention that they be sterilised before use, the instructions for cleaning and sterilisation must be such that, if correctly followed, the device will still comply with the requirements in Section I."

Section I states:

"The devices must be designed and manufactured in such a way that, when used under the conditions and for the purposes intended, they will not compromise the clinical condition or the safety of patients, or the safety and health of users or, where applicable, other persons, provided that any risks that may be associated with their use constitute acceptable risks when weighed against the benefits to the patient and are compatible with a high level of protection of health and safety."

Reprocessing of single use items without taking due regard of these documents, may place an individual or the organisation for whom they work, or both, at risk of prosecution under the liability provisions of Part 1 of the Consumer Protection Act 1987 if the product is found to be defective (that is, does not provide the expected level of safety) and may be committing a criminal offence under the Health and Safety at Work Act 1974 by contravening the provisions relating to "general duties" by carrying out activities which expose patients or staff to risk.

Worries about the legal and regulatory position had also transmitted themselves to manufacturers and their representative bodies. The ABHI (Association of British Healthcare Industries), ${ }^{3}$ AAMI (Association for the Advancement of Medical Instrumentation), ${ }^{4}$ and EUCOMED (European Confederation of Medical Devices Associations $)^{5}$ have all issued documents advising their members of the difficulties that they might place themselves in by turning a blind eye to the problems inherent in the reuse of single use accessories and also the difficulties of proving that reusable accessories are appropriately clean and reprocessed.

With this background, the Endoscopy Committee of the British Society of Gastroenterology decided in November 1995 to set up a working party to attempt to issue sensible advice on these issues to gastroenterologists, endoscopy units, trusts, and manufacturers in a new and complex situation.

\section{Scientific background}

Concern about the reuse of endoscopic accessories centres around two main areas, the first and most important being sterility and the second being the ability of the equipment to perform its functions after repeated uses and sterilisations.

It is perhaps unfortunate that gastrointestinal endoscopy finds itself judged in the same area as cardiac and angiographic techniques and renal dialysis. The American CDC description of equipment as non-critical, semicritical, and critical, defines endoscopes, being equipment used across intact mucous membranes, as being semicritical and, therefore, requiring high level disinfection such as mechanical cleaning and a 10 minute glutaraldehyde soak. The 10 minute soak has however been questioned recently. ${ }^{67}$ Biopsy forceps and any other accessory which penetrates the mucosa, must be defined as critical and, therefore, should be sterile. In the European system, devices have to be classified as Class $\mathrm{I}, \mathrm{II}^{\mathrm{a}}$, $\mathrm{II}^{\mathrm{b}}$, or III, the highest number relating to the highest risk devices-for example, those which come into direct contact with vital body parts such as heart or spinal cord. In this system, endoscopes and their accessories will usually be in Class $\mathrm{I}_{\text {or }} \mathrm{II}^{\mathrm{a}}$. $^{2}$ 
The impossibility of maintaining sterility of a device which passes through the biopsy/suction channel of a gastrointestinal endoscope is apparent to all endoscopists. The endoscope is not sterile, the procedures for handling the accessory in the endoscopy suite are not sterile, and the gastrointestinal tract is certainly not sterile. Nevertheless, the avoidance of cross contamination remains an important consideration, even though no cases of endoscope or accessory transmitted infection have been reported in the UK since the publication of the British Society of Gastroenterology recommendations for cleaning endoscopes in $1988 .^{8}$

Similarly, the consequences of accessory failure in gastrointestinal endoscopy are not as calamitous as they may be in coronary angiography, for example. If a balloon bursts in the bile duct, it can be replaced with little loss, other than time. This is not the case in blood vessels. Plastic stents may disintegrate in the bile duct, but these are not in a sterile environment and stents are never reused in any case. Furthermore, implantable devices which have shown failures in angiographic and cardiological practice are not currently used in gastroenterology.

\section{Practical considerations}

The Working Party felt that it would be impractical for any trust or any group of trusts, to establish cleaning and sterilising procedures for endoscopic accessories with the appropriate quality control to ensure that single use items could be reused with a high degree of sterility and no appreciable deterioration in function. The Medical Devices Agency has no funds for this purpose and the Department of Health has apparently allocated no resources to perform the task on our behalf; we must therefore rely on the manufacturers.

It is worth drawing attention here to a difference in regulation on the two sides of the Atlantic. American based endoscopy accessory companies have generally decided that the current requirements of the Food and Drug Administration regarding the demonstration of effective reprocessing are so demanding that it is not cost effective for companies to undertake the necessary testing. It is easier, and safer for them, to make devices single use. It is, however, very expensive for the end user ${ }^{9}$ and there is some evidence that manufacturers in the United States have begun to realise that the costs of a fully disposable service are unacceptable, even in America.

In Europe, cost issues have historically been more important, and the need to recycle expensive medical plastics, especially in Germany, has led to the continuing manufacture of reusable accessories, often alongside a single use range. Naturally, safe reuse of reusable accessories requires that instructions for cleaning are followed meticulously, the sterilisers are of the appropriate type, and are carefully monitored for performance. ${ }^{410}$ Local, regular bacteriological audit is appropriate and should be part of established practice for gastrointestinal endoscopy units. ${ }^{11}$

The ability to clean and disinfect endoscopic accessories without autoclaving is not established. In the United States, the FDA has recently required manufacturers to prove that the chemicals they recommend for disinfecting their devices, such as glutaraldehyde or peracetic acid, work in the equipment to be cleaned and not simply in a bench test on a piece of similar material. This has stimulated some discussion. ${ }^{12}$ Similarly, variation in sterilisation procedures from hospital to hospital, machine to machine, and batch to batch, makes it difficult for manufacturers to be sure that even their reusable accessories are sterile at the time they are removed from their packets. ${ }^{13}$ It seems that both endoscopes and accessories are undergoing redesign so that they can more easily be cleaned, disinfected, and/or sterilised, but complex accessories, such as spiral wound biopsy forceps, will always present difficulties.

The American Society for Gastrointestinal Endoscopy (ASGE) concluded in October $1992^{14}$ that "issues in considering the use of disposable endoscopic accessories include their efficacy, safety, and cost. Unfortunately, objective information to address these complex concerns is, for the most part, lacking. The decision about the appropriate use of disposable devices must be individualised". The ASGE also stated that "whenever hospitals and physicians reuse devices labelled 'for single use only'... they are perceived to be taking a risk for the liability resulting from infectious agent transmission or malfunction of the equipment. However, as with so many actions by hospitals and physicians, the risk must be weighed against the potential benefit". In the UK, we may not take this risk, as reuse of a single use device could give rise to an offence under the Consumer Protection Act 1987 or through the Health and Safety at Work Act 1974 which may be punishable by imprisonment. ${ }^{15}$

\section{Specific accessories}

There are few studies comparing efficacy and/or cost of reusable versus disposable accessories and most relate to biopsy forceps. Two studies found that single use forceps produced smaller biopsy specimens and suffered more mechanical failures. ${ }^{16}{ }^{17}$ Recent developments in forceps design may make these publications out of date. Two other studies have given conflicting views on the relative costs of reusable versus single use forceps. The Kozarek group from Seattle found that reusable biopsy forceps were more cost effective after seven uses ${ }^{18}$ while a British endoscopy unit estimated that an annual saving of $£ 32585$ could be made by using single use forceps (Atkins, 1995, unpublished). The latter study was an estimate and not a prospective trial. As far as other accessories are concerned, there are few data on which to base sensible decisions. One study showed that single use equipment had an enormous impact on the costs of endoscopic retrograde cholangiopancreatography (ERCP) ${ }^{11}$ but there have been no studies comparing the efficacy of disposable versus reusable ERCP or colonoscopic accessories. Therefore, rough guidelines only can be given and these may change (see table 1). A recent study from Canada ${ }^{19}$ has shown that ERCP sphincterotomes and retrieval baskets can be reused safely eight and 13 times respectively (without undue deterioration in function). There was a large calculated cost saving compared with single use items. Furthermore, in the USA, a recent study has shown that sphincterotomy knives designated single use can be sterilised using ethylene oxide and reused up to 10 times. $^{20}$

Accessories can be classified into three groups. The first category is those which are always supplied as reusable equipment and can, following appropriate cleaning, disinfection, or sterilisation according to the manufacturers' instructions, be reused. Such reuse may not be unlimited and it is the responsibility of the users to record the number of times a piece of equipment has been reprocessed and to examine it carefully to assess that it is still functional before each reuse. The second category, mainly reflecting relatively low cost items, is for those which are always single use. The third category reflects those where there is some degree of choice between reusable or single use items. It seems that at the moment, in practical terms, there is no possibility of the reuse of single use equipment in this country because of the legal constraints already referred to. A further practice which may be damaged by this ruling is the reuse of expensive laser fibres for the same patients when they return for a repeat treatment. Simple cleaning is 
Table 1 Guidelines for classification of specific accessories

\begin{tabular}{|c|c|c|c|}
\hline Accessory & $\begin{array}{l}\text { Reusable after } \\
\text { cleaning/ } \\
\text { disinfection } \\
\text { according to } \\
\text { manufacturers } \\
\text { instructions }\end{array}$ & $\begin{array}{l}\text { Single } \\
\text { use only }\end{array}$ & $\begin{array}{l}\text { Reusable or } \\
\text { single use items. } \\
\text { Choice depends } \\
\text { on local factors. } \\
\text { Do not reuse } \\
\text { "single use" } \\
\text { devices }\end{array}$ \\
\hline \multicolumn{4}{|l|}{ Oesophagogastroduodenoscopy } \\
\hline Forceps & & & 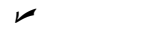 \\
\hline Cytology brushes & & $\boldsymbol{}$ & \\
\hline $\begin{array}{l}\text { Oesophageal dilatation } \\
\text { devices }\end{array}$ & & & $\boldsymbol{}$ \\
\hline Varices injection needles & & $\boldsymbol{\nu}$ & \\
\hline \multicolumn{4}{|l|}{ ERCP } \\
\hline Cannulae & & & レ \\
\hline Sphincterotomes & & & 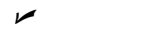 \\
\hline Dilatation balloons & & $\boldsymbol{r}$ & \\
\hline Retrieval balloons & & $r$ & \\
\hline Dormia baskets & & & $\boldsymbol{\nu}$ \\
\hline Lithotripters & & & $\boldsymbol{}$ \\
\hline Stents & & $\boldsymbol{\nu}$ & \\
\hline Stent guiding catheters & & & $\boldsymbol{\nu}$ \\
\hline Stent pushers & & & $\boldsymbol{\nu}$ \\
\hline Guide wires & & レ゙ & \\
\hline Stent retrieval forceps & 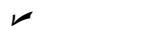 & & \\
\hline Soehendra stent retriever & & $\boldsymbol{\nu}$ & \\
\hline \multicolumn{4}{|l|}{ Colonoscopy } \\
\hline Snares & & & $\boldsymbol{\nu}$ \\
\hline Forceps & & & $\nu$ \\
\hline
\end{tabular}

${ }^{\star}$ Some Nitinol wires are now labelled for more than one use.

all that is done, which would seem unlikely to damage the fibres but the Working Party's interpretation of the regulations is that even this practice must be abandoned unless the institution concerned is happy to assume legal liability for the functioning of the fibres.

One US Army facility has recently declared unilaterally that its procedures are adequate for the reuse of single use endoscopic accessories following internal assessment of reprocessing schedules and results. The legal concerns for this body are not the same as for civilian health care facilities. ${ }^{21}$ One civilian hospital in the USA has, however, taken a similar line. ${ }^{22}$

This Working Party of the British Society of Gastroenterology questions, for reasons given above, whether the current guidelines suggested by MDA DB $9501^{1}$ are entirely appropriate, but unless they are altered there is currently no choice but to comply.

The recommendations of this BSG Working Party, therefore, are as follows:

(1) Reusable accessories should be used where appropriate and where cleaning and sterilisation procedures, using manual methods, ultrasonic cleaners and autoclaves, are demonstrably and regularly shown to be bacteriologically sound. If these guidelines cannot be followed, single use accessories should be used. Reusable accessories may have a limited life span; manufacturers' advice must be taken and the accessories inspected before each cleaning cycle and immediately prior to use, and discarded if the manufacturer's criteria for reuse are not met. Using seriously worn equipment is dangerous, makes procedures more difficult, and may damage endoscopes.

(2) Single use items must not be reused unless the strictures referred to in MDA DB 9501 can all be adhered to.

(3) Manufacturers should work with users as well as regulatory bodies to maintain both single use and reusable accessory ranges and issue appropriate advice for reusable items on which methods of cleaning/ disinfection/sterilisation have been validated.

Costs of endoscopic procedures will rise and this may put additional strains on local commissioning authorities or directorates of gastroenterology/endoscopy. Members are advised to bring this to the attention of their managers and clinical directors and to enter into negotiations early with commissioning authorities for an increase in price where appropriate. It would seem that risk management criteria, if applied to the area of endoscopic accessory reprocessing, would suggest that the lives saved would be prohibitively expensive. Trusts, however, may reflect that possible legal bills would make it money well spent. Further work by manufacturers or academic institutions to extend the range of reusable accessories would be welcome. Further research to prove the value or lack of value of the very expensive recommendations contained in this report would also be helpful.

Guy's Hospital, London SE1 9RT, UK

M WILKINSON N SIMMONS

Middlesborough General Hospital,

M BRAMBLE

Cleveland TS5 5AZ, UK

St George's Hospital, London SW17 ORE, UK

R LEICESTER

Endoscopy Unit, Rotherham General Hospital Trust,

J D'SILVA

Rotherham S60 1UD, UK

Cook UK Limited, Hertfordshire SG6 1LN, UK

R BOYS

Keymed, Essex SS2 5QH, UK

R GRAY

Correspondence to: Dr Wilkinson.

1 Medical Devices Agency. The reuse of medical devices supplied for single use only. Medical Devices Agency Bulletin, MDA DB 9501, January 1995. only. Medical Devices Agency Bulletin, MDA DB 9501, January 1995.
Council Directive 93/42/EEC of 14 June 1993 concerning medical devices. Council Directive 93/42/EEC of 14 June 1993 concerning medical devices.
Official fournal of the European Communities. L169, Vol 36, 12 July 1993.

Official fournal of the European Communities. L169, Vol 36, 12 July 1993.
Association of the British Healthcare Industries. ABHI position paper on reuse Association of the British Healthcare
of medical devices. ABHI, June 1994.

4 Association for the Advancement of Medical Instrumentation. Designing, testing and labeling reusable medical devices for reprocessing in health care facilities: a guide for device manufacturers. AAMI Technical Information Report No 12, 1994.

5 European Confederation of Medical Devices Associations. The case against reuse of single use medical devices. EUCOMED, 1995.

6 Urayama S, Kozarek RA, Sumida S, Raltz S, Merriam L, Pathigal P. Mycobacteria and glutaraldehyde: is high-level disinfection of endoscopes possible? Gastrointest Endosc 1996;43:451-6.

7 ACG, AGA, ASGE, SGNA. Position statement. Reprocessing of flexible gastrointestinal endoscopes. Gastrointest Endosc 1996;43:540-6.

8 Weller IVD, Williams CB, Jeffries DJ, et al. Cleaning and disinfection of equipment for gastrointestinal flexible endoscopy: interim recommendaequipment for gastrointestinal flexible endoscopy: interim recommenda-
tions of a working party of the British Society of Gastroenterology. Gut tions of a working
$1988 ; 29: 1134-51$.

9 Raltz S, Kozarek RA, Kim-Deobald J, Pethigal P, Moorhouse MA. The impact of disposable equipment on room fee reimbursement for endoscopic retrograde cholangio-pancreatography. Gastroenterology Nursing 1994;17:14-6.

10 Medical Devices Agency. Sterilisation, disinfection and cleaning of medical devices and equipment: guidance on decontamination from the Micriobiology Advisory Committee to the Department of Health.

11 Merighi A, Contato E, Scagliarini R. Quality improvement in gastrointestinal endoscopy: microbiologic surveillance of disinfection. Gastrointest Endosc 1996;43:457-62.

12 Prince R. EPA and FDA efficacy-testing requirements for chemical germicides and reprocessed devices. Medical Device $\mathcal{E}$ Diagnostic Industry, May 1995:152-60.

13 Whitbourne J, Kuhnert S, Monnat K. Validating the cleaning, disinfection and sterilization of reusable medical devices. Medical Device $\mathcal{E}$ Diagnostic Industry, June 1994:68-74.

14 American Society for Gastrointestinal Endoscopy. Technology assessment status evaluation: disposable endoscopic accessories. ASGE, October 1992.

15 Association of Medical Microbiologists. Reusing medical devices. Association of Medical Microbiologists position paper, 1995.

16 Yang R, Viutch F, Wright K, et al. Adequacy of disposable biopsy forceps for gastrointestinal endoscopy: a direct comparison with reusable forceps. Gastrointest Endosc 1990;36:379-82.

17 Turk DK, Kozarek RA, Botoman VA, et al. Disposable endoscopic biopsy forceps: comparison with standard forceps of sample size and adequacy of specimens. F Clin Gastroenterol 1991;13:76-8.

18 Kozarek RA, Raltz SL, Merriam LD, Sumida SE. Disposable versus reusable biopsy forceps: a prospective evaluation of costs. Gastrointest Endosc 1996;43:10-3.

19 Cohen J, Haber GB, Kortan P, et al. A prospective study of the repeated use of sterilized papillotomes and retrieval baskets for ERCP: quality and cost analysis. Gastrointest Endosc 1997;45:122-7.

20 Kozarek RA, Sumida SE, Raltz SL, Merriam LD, Irizarry DC. In vitro evaluation of wire integrity and ability to reprocess single-use sphincter-

21 Parker A, Kadakia SC, Howell G, Pesetski J. Reuse of single use suppliesthe pendulum swings [abstract]. Gastroenterology 1996;110:A885.

22 Kozarek RA and the VMMC Reuse Committee. Reuse of disposable Kozarek RA and the VMMC, Reuse Committee. Reuse of disposable
equipment: one medical center's approach to the problem [abstract]. Gastrointest Endosc 1995;41:323. 